\title{
Relation of Pulse Rate with Flu Medication Treatment
}

\author{
Muhammad Imran Qadir and Bushra Khalid* \\ Institute of Molecular Biology and Biotechnology, Bahauddin Zakariya University, Pakistan
}

*Corresponding author: Bushra Khalid, Institute of Molecular Biology and Biotechnology, Bahauddin Zakariya University, Multan, Pakistan.

Received Date: September 16, 2019

Published Date: September 25, 2019

\begin{abstract}
Influenza is caused by Influenza virus which has many types A, B, C and D. Each type is divided into subtypes like Influenza A (H1N1 and H3N2) are most common. Its symptoms have resemblance with cold but if it is not treated properly then many nearby healthy individual also affected by flu. Vaccination is best way for prevention but some people prefers medication while other prefer home remedies for flu treatment. Heart is muscular organ which is responsible for blood pumping moreover a healthy pulse rate declare that heart is at right state. Abnormal pulse rate is associated with many other illnesses. To measure the pulse rate, hold the hand as its palm side up and by placing the two fingers on wrist feel pulse rate and count it for one minute by using stopwatch. Finally, here is significant relation is observed for flu treatment with pulse rate.
\end{abstract}

\section{Introduction}

Influenza virus leads influenza or flu which is highly contagious disease. Its symptoms are related to cold but it differs in some aspect like causing agent Rhino virus for flu and influenza virus for influenza. Influenza virus has four types A, B, C and D further $A$ and $B$ cause seasonal influenza. Among them H1N1 and H3N2 are common subtypes of influenza type $\mathrm{A}$ and other subtypes lead sporadic human infection [1]. Vaccine provide protection against influenza A (H1N1) and Influenza B rather than influenza A (H3N2) [2]. To understand the host pathogenicity relationship, structural composition of Influenza virus is noticed mean Influenza virus is RNA enveloped and belong to Orthomyxoviridae family. It consists helical capsid mediated by matrix protein M1 and M2, neuraminidase and hemagglutinin act as glycoprotein and involved in enveloped formation. It is easily penetrated in epithelial cells of human respiratory tract. Its structural evolution via antigen drift and antigenic shifting facilitate in its pathogenicity and scientists need revision in vaccine formulation each year [3]. Heart is muscular organ which is present in the center of chest near left side and responsible to pump oxygenated blood to all body parts and receive deoxygenated blood and pump toward lungs to receive oxygen. Healthy heart is responsible to deliver oxygen at right amount irrespective of activity. Pulse rate and heartbeat declared the health of heart but both are confusing term but pulse declared the expansion and contraction of arteries in response to heart pumping, so both are considered equal [4]. Pulse rate increase in many diseases and it can measure at upper arm, wrist and neck. Slow pulse rate with dizziness helped to identify internal bleeding and other serious conditions while fast pulse rate is in the case of high blood pressure and cardiovascular problems. A healthy pulse rate is between 60 and 100 beats per minutes in adults. Infants have up to $160 \mathrm{bpm}$ which decrease with the passage of age. A healthy and fit person has slow pulse rate as compared to those persons who exercise less and suffered with some health issues [5].

\section{Materials and Methods}

\section{Materials}

Stopwatch, notepad

\section{Methodology}

There are many places where heartbeat can measure like top or inner side of feet and behind the knees etc. Arteries runs closely to the surface of skin especially wrist and neck. To measure the pulse rate firstly turn one hand over in such a way palm-side up. Gently placed two fingers in the groove of forearm. By placing fingers at right side feel pulse rate and at the same time set the stopwatch for one minute and measure the pulse rate as per minute. Another method in which gentle place the fingers at soft groove on either side of windpipe. Count the pulse rate in one minute and note down on the page. 


\section{Results and Discussion}

We counted pulse rate by using stopwatch for 60 seconds. Here Graph show the number of individuals whose pulse rate were noticed with respect of flu treatment with and without medicine. Out of 30 males and 70 females only 10 males and 25 females treat flu with medicine while they treat flu without medication (Table 1). shows the average value with standard deviation Further T-test is also performed to check its significance (Figure 1) (Table 1).

$$
\mathrm{p}<0.1=\text { Non-significant }
$$

Table 1: Relation of Pulse rate with flu treatment with and without medicines.

\begin{tabular}{|c|c|c|c|c|}
\hline Sr no. & Gender & $\begin{array}{c}\text { Medicine } \\
\text { dependent } \\
\text { treatment }\end{array}$ & $\begin{array}{c}\text { Flu treatment } \\
\text { Without } \\
\text { medicine }\end{array}$ & p value \\
\hline 1 & Male & $80.8 \pm 8.17$ & $79.65 \pm 11.84$ & 0.78 \\
\hline 2 & Female & $79.36 \pm 11.74$ & $74.15 \pm 9.20$ & 0.04 \\
\hline 3 & Both & $76.01 \pm 10.40$ & $80.03 \pm 10.62$ & 0.08 \\
\hline
\end{tabular}

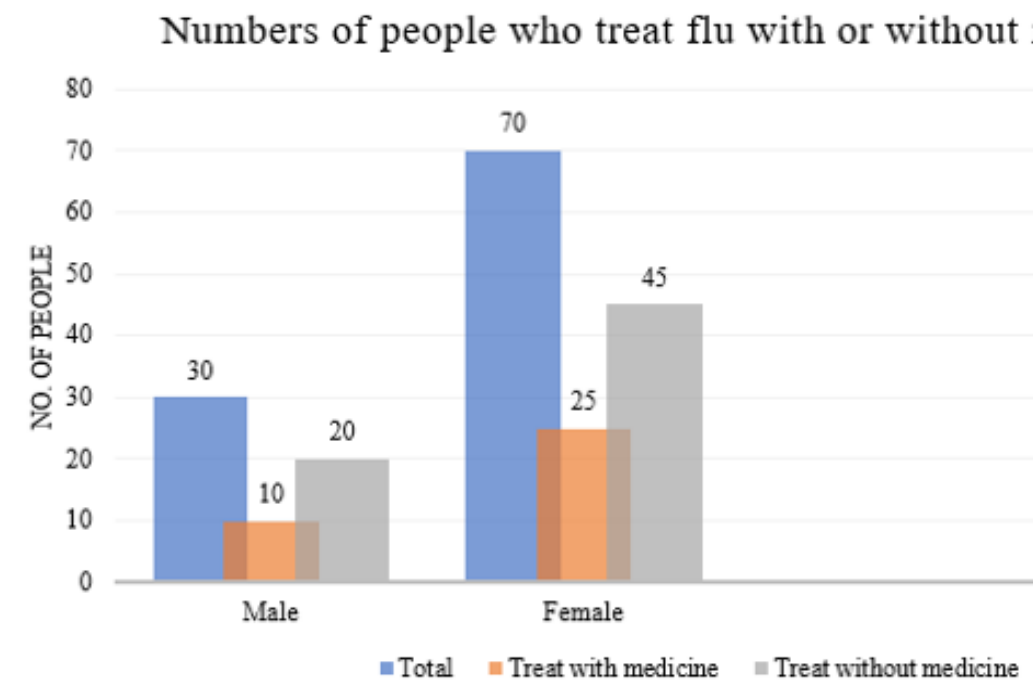

Figure 1: Numbers of people who treat flu with or without medication.

\section{Conclusion}

There is significant relation observed for flu treatment with pulse rate.

\section{Acknowledgement}

None

\section{Conflict of Interest}

No conflict of interest.

\section{References}

1. Park JE, Ryu Y (2018) Transmissibility and severity of influenza virus by subtype. Infect Genet Evol 65: 288-292.

2. Blut A (2009) Influenza virus. Transfusion Medicine and Hemotherapy 36(1): 32-39.

3. Abreu R, Ross TM (2018) Influenza-A new pathogen every year. Current Opinion in Systems Biology 12: 12-21.

4. Yuan G, Drost NA, McIvor RA (2013) Respiratory rate and breathing pattern. McMaster University Medical Journal 10(1): 23-25.

5. Pickering D (2013) How to measure the pulse. Community Eye Health 26(82): 37. 